\title{
Determinants for the improved thermostability of a mesophilic family 11 xylanase predicted by computational methods
}

\author{
Huimin Zhang ${ }^{1 \dagger}$, Jianfang $\mathrm{Li}^{1 \dagger}$, Junqing Wang ${ }^{2}$, Yanjun Yang ${ }^{1}$ and Minchen $\mathrm{Wu}^{3^{*}}$
}

\begin{abstract}
Background: Xylanases have drawn much attention owing to possessing great potential in various industrial applications. However, the applicability of xylanases, exemplified by the production of bioethanol and xylooligosaccharides (XOSs), was bottlenecked by their low stabilities at higher temperatures. The main purpose of this work was to improve the thermostability of AuXyn11A, a mesophilic glycoside hydrolase (GH) family 11 xylanase from Aspergillus usamii E001, by N-terminus replacement.

Results: A hybrid xylanase with high thermostability, named AEXynM, was predicted by computational methods, and constructed by substituting the N-terminal 33 amino acids of AuXyn11A with the corresponding 38 ones of EvXyn11 $1^{\mathrm{TS}}$, a hyperthermostable family 11 xylanase. Two AuXyn11A- and AEXynM-encoding genes, Auxyn $11 \mathrm{~A}$ and AExynM, were then highly expressed in Pichia pastoris GS115, respectively. The specific activities of two recombinant xylanases (reAuXyn11A and reAEXynM) were 10,437 and 9,529 $\mathrm{U} \mathrm{mg}^{-1}$. The temperature optimum and stability of reAEXYnM reached 70 and $75^{\circ} \mathrm{C}$, respectively, much higher than those $\left(50\right.$ and $\left.45^{\circ} \mathrm{C}\right)$ of reAuXyn $11 \mathrm{~A}$. The melting temperature $\left(T_{m}\right)$ of reAEXynM, measured using the Protein Thermal Shift (PTS) method, increased by $34.0^{\circ} \mathrm{C}$ as compared with that of reAuXyn11A. Analyzed by HPLC, xylobiose and xylotriose as the major hydrolytic products were excised from corncob xylan by reAEXynM. Additionally, three single mutant genes from AExynM (AExynM ${ }^{C 5 T}$, $A E x y n M^{P 9 S}$, and $A E x y n M^{H 14 N}$ ) were constructed by site-directed mutagenesis as designed theoretically, and expressed in P. pastoris GS115, respectively. The thermostabilities of three recombinant mutants clearly decreased as compared with that of reAEXYnM, which demonstrated that the three amino acids $\left(\mathrm{Cys}^{5}\right.$, Pro $^{9}$, and $\mathrm{His}^{14}$ ) in the replaced $\mathrm{N}$-terminus contributed mainly to the high thermostability of AEXynM.

Conclusions: This work highly enhanced the thermostability of AuXyn11A by N-terminus replacement, and further verified, by site-directed mutagenesis, that $\mathrm{Cys}^{5}$, $\mathrm{PrO}^{9}$, and $\mathrm{His}^{14}$ contributed mainly to the improved thermostability. It will provide an effective strategy for improving the thermostabilities of other enzymes.
\end{abstract}

Keywords: Xylanase, Thermostability, Computational method, N-terminus replacement, Site-directed mutagenesis, Xylooligosaccharides

\section{Background}

Xylan, the major constituent of hemicellulose, is a heterogeneous polysaccharide with a backbone of $\beta$-1,4-D-linked xyloses, and abundantly present in agricultural wastes, such as corncob, wheat bran, and bagasse [1,2]. Because of its heterogeneity and complexity, the complete degradation

\footnotetext{
*Correspondence: biowmc@126.com

'Equal contributors

${ }^{3}$ Wuxi Medical School, Jiangnan University, 1800 Lihu Avenue, Wuxi, Jiangsu

214122, China

Full list of author information is available at the end of the article
}

of xylan is a more complex procedure that requires the synergistic action of several xylanolytic enzymes. Among them, xylanase (endo- $\beta-1,4-\mathrm{D}$-xylanase, EC 3.2.1.8) is a key enzyme in that it cleaves the internal $\beta-1,4-\mathrm{D}$-xylosidic linkages of xylan to yield different chain lengths of xylooligosaccharides (XOSs) [3]. Enzymes with xylanolytic activity have been classified into several glycoside hydrolase (GH) families (http:/www.cazy.org/fam/acc_GH. html), whereas most xylanases belong to $\mathrm{GH}$ families 10 and 11 [1]. The overall three-dimensional structure of family 11 xylanases consists mainly of one $\alpha$-helix

\section{Biomed Central}


and two $\beta$-sheets which are packed against each other, resembling a partially closed right hand [4].

Recently, it has been increasingly recognized that xylanase plays an important role in lignocellulosic biodegradation. For example, xylanase, used in bioethanol production from lignocellulosic materials, could promote the hydrolysis of cellulose by decomposing xylan which restricts the access of cellulase to the cellulose surface [5]. Unfortunately, most wild-type xylanases are poor in thermostability, which prevented them from being used in bioprocesses where high temperatures were required to improve the availability and solubility of substrates, and to reduce the viscosity and microbial contamination of the reaction solution [6]. Although some thermostable xylanases were isolated from thermophiles, their expression levels and/or specific activities were much lower, making them unable to be used efficiently $[7,8]$. Therefore, it is desirable to improve the thermostabilities of mesophilic xylanases by genetic engineering. As far as we know, some domains or local regions affecting protein thermostability, such as salt bridge, hydrogen bond, charged surface residue, disulfide bridge, and $\mathrm{N}$ - or $\mathrm{C}$-terminus, have been revealed $[9,10]$. Among those factors, the importance of the Nterminus in maintaining xylanase thermostability was highlighted by some researchers $[11,12]$.

EvXyn $11^{\mathrm{TS}}$ is one of the most thermostable of GH family 11 xylanase as reported previously [13]. In our previous work, a mesophilic family 11 xylanase (AuXyn11A) was isolated from Aspergillus usamii E001, having high specific activity, broad $\mathrm{pH}$ stability, and strong resistance to metal ions and ethylene diamine tetraacetic acid (EDTA) [14]. Then, the AuXyn11A-encoding gene, Auxyn11A, was cloned [15]. The homology alignment, conducted using the DNAMAN 6.0 software (Lynnon, Pointe-Claire, QC, Canada), displayed that the primary structure of AuXyn11A shared $62.4 \%$ identity with that of EvXyn $11^{\mathrm{TS}}$, but the identity of $\mathrm{N}$-terminal 38 amino acids (numbered by $E v \mathrm{Xyn} 11^{\mathrm{TS}}$ ) between them was $36.8 \%$. That, to some extent, implied the significance of the xylanase $\mathrm{N}$-terminus to its thermostability. In this work, the suitable N-terminal region of AuXyn11A to be substituted by the corresponding one of EvXyn $11^{\mathrm{TS}}$ was predicted by computational methods, and a hybrid gene, $A E x y n M$, was constructed by megaprimer PCR as designed theoretically. Two genes, Auxyn $11 A$ and AExynM, were then expressed in Pichia pastoris GS115, respectively. In addition, based on the computational design, three genes, $A E x y n M^{\mathrm{C} 5 \mathrm{~T}}$, $A E x y n M^{\mathrm{P} 9 \mathrm{~S}}$, and $A E x y n M^{\mathrm{H} 14 \mathrm{~N}}$, were obtained by sitedirected mutagenesis, and expressed in $P$. pastoris, respectively. The temperature characteristics of reAuXyn11A, reAEXynM, and three recombinant single mutants were analyzed and compared. Finally, the action of reAEXynM or reAuXyn11A on corncob xylan was analyzed by HPLC. To our knowledge, this is the first report on the determinants for the improved thermostability of a mesophilic GH family 11 xylanase predicted by computational methods, as well as experimented by $\mathrm{N}$-terminus replacement and site-directed mutagenesis.

\section{Results and discussion}

\section{Computational prediction of the hybrid xylanase}

It has been demonstrated that the conformation of mesophilic protein is more flexible than that of the thermophilic one [16]. To quantify the flexibility of protein, the notion of B-factor values was introduced to reflect smearing of atomic electron densities with respect to their equilibrium positions as a result of thermal motion and positional disorder [17]. In this work, the B-factor values of AuXyn11A and EvXyn $11^{\mathrm{TS}}$ were calculated by using the B-FITTER program (Figure 1A). After comparing the B-factor values between them, the N-terminal segment from $\mathrm{Ser}^{1}$ to $\mathrm{Ala}^{33}$ of AuXyn11A was selected, corresponding to the most pronounced degrees of thermal motion, namely flexibility. As a result, the AEXynM was designed by substituting the $\mathrm{N}$-terminus of AuXyn11A with the corresponding one from $\mathrm{Asn}^{1}$ to $\mathrm{Arg}^{38}$ of $E v \mathrm{Xyn} 11^{\mathrm{TS}}$ (Figure 1B).

The three-dimensional structures of AuXyn11A, AEXynM, and $E v X y n 11^{\mathrm{TS}}$ were homologically modeled, and subjected to molecular dynamics (MD) simulation processes, followed by calculating their root mean square deviation (RMSD) values, respectively (Figure 2A). The MD simulation trajectory of AEXynM was almost equal to that of $E v X y n 11^{\text {TS }}$. However, the RMSD value of AuXyn11A after equilibration was much larger than that of AEXynM or $E v X y n 11^{\text {TS }}$. Simultaneously, the distributions of RMSD values (that is, atomic displacement ranges) of AuXyn11A and AEXynM were statistically analyzed, respectively, using the Origin8 software (Figure 2B). The RMSD values of AuXyn11A were mainly focused on $1.05 \AA$ and those of AEXynM on $0.45 \AA$, indicating that AEXynM was much more rigid than AuXyn11A. Based on the analytical result that the rigidity of a protein was positively related to its thermostability [18], the designed hybrid xylanase AEXynM was predicted to be more thermostable than the wild-type xylanase AuXyn11A.

\section{Construction and expression of $A E x y n M$}

An approximate 120 bp band of the DNA fragment SyX was amplified from pUCm-T-Syxyn11 by first-round PCR with primers SyX-F and SyX-R. Then, using pUCm-T-Aux$y n 11 A$ as the template, a complete hybrid gene AExynM of 600 bp was amplified by second-round PCR with primers SyX and AuX-R. The DNA sequencing result verified that the cloned $A E x y n M$ was exactly 596 bp in length (containing EcoRI and NotI sites), coding for a hybrid xylanase AEXynM of 193 amino acids. The homology alignment of amino acid sequences indicated that the identities of 

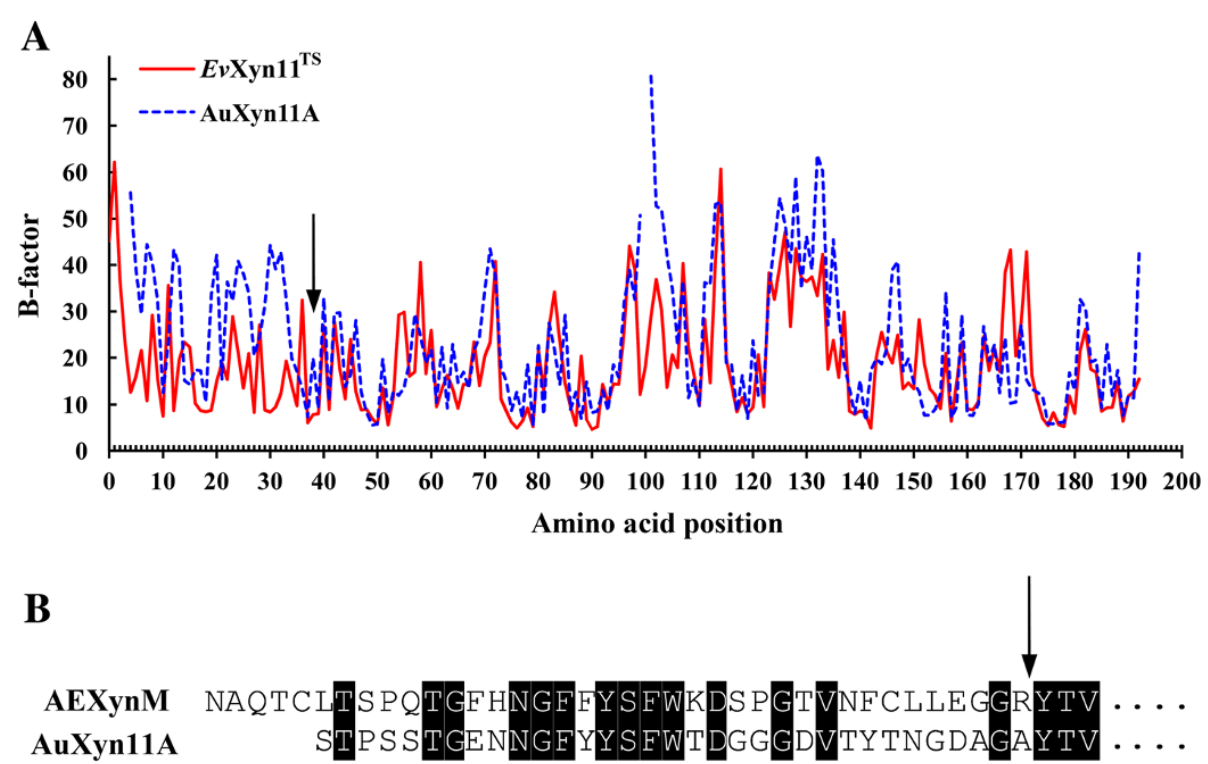

Figure 1 Computational prediction of AEXynM by comparison of B-factor values. (A) The B-factor values of amino acid residues of AuXyn11A (dashed line) and EvXYn11 A ${ }^{\text {TS }}$ (solid line) were calculated after a $15 \mathrm{~ns} \mathrm{MD}$ simulation process at a temperature of $300 \mathrm{~K}$. (B) The homology alignment of $\mathrm{N}$-terminal sequences between AEXynM and AuXyn11A. The site of $\mathrm{N}$-terminus replacement is marked with a bold arrow. MD, molecular dynamics.

AEXynM with AuXyn11A and EvXyn11 ${ }^{\mathrm{TS}}$ were 87.6 and $74.7 \%$, respectively.

The $P$. pastoris transformant that could resist higher concentrations of geneticin G418 might contain multiple copies of integration of a heterologous gene into the $P$. pastoris genome, which could potentially lead to a higher expression level of the heterologous protein as elucidated in the manual of the Multi-Copy Pichia Expression Kit (Invitrogen, Carlsbad, CA, USA). The protein expression level, however, was not directly proportional to the concentration of G418 [19]. Therefore, all P. pastoris transformants, resistant to $1.0,2.0$, and $4.0 \mathrm{mg} \mathrm{mL}^{-1}$ of G418, were picked out for flask expression tests. After the transformants were induced by adding $1.0 \%(\mathrm{v} / \mathrm{v})$ methanol at 24-hour intervals for 72 hours, their cultured supernatants were harvested and used for xylanase activity and protein assays, respectively. Among all tested transformants, two recombinant strains, labeled as $P$. pastoris GSAu4-2 and GSAEM4-8, expressing the highest reAuXyn11A and reAEXynM activities of 646.6 and $580.8 \mathrm{U} \mathrm{mL}^{-1}$,
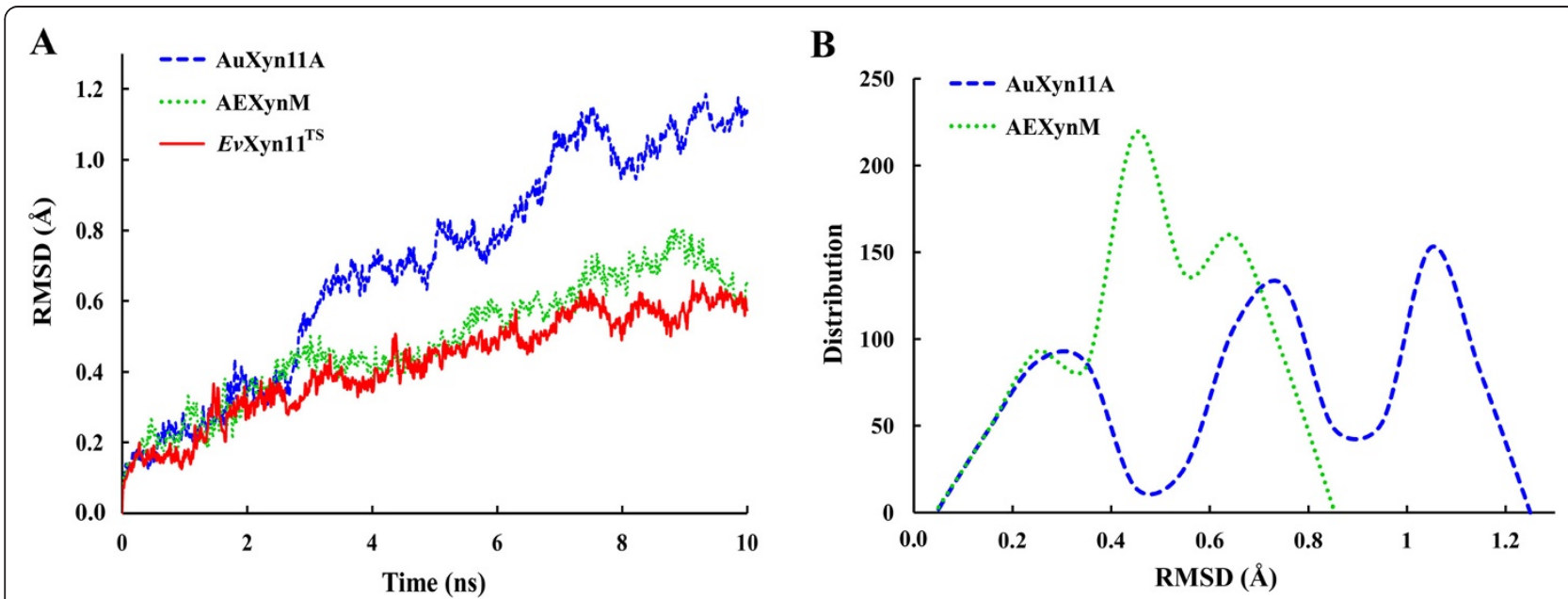

Figure 2 Calculation and distribution of the RMSD values. (A) The curves of RMSD values of AuXyn11A (dashed line), AEXynM (dotted line), and EvXyn11 $1^{\text {TS }}$ (solid line), respectively, after MD simulation processes at $500 \mathrm{~K}$ for $10 \mathrm{~ns}$. (B) The distributions of RMSD values of AuXyn11A (dashed line) and AEXynM (dotted line), respectively. MD, molecular dynamics; RMSD, root mean square deviation. 
respectively, were screened. No xylanase activity was detected in the cultured supernatant of the P. pastoris GSC under the same expression conditions.

\section{Purification of reAuXyn11A and reAEXynM}

One of the advantages of the $P$. pastoris expression system was that the purities of expressed recombinant proteins were very high according to the description of the MultiCopy Pichia Expression Kit, which could greatly simplify the purification procedures. It was reported that the purity of the recombinant $A$. usamii xylanase D (reAuXyn11D) expressed in P. pastoris was more than 85\% [20]. In this work, the amount of expressed reAuXyn11A or reAEXynM, assayed by protein band scanning, accounted for over $82 \%$ of that of total protein (Figure 3, lane 1 or 3 ). Therefore, reAuXyn11A or reAEXynM was purified to homogeneity only by a simple combination of ammonium sulfate precipitation, ultrafiltration, and Sephadex G-75 gel filtration, displaying a single protein band with an apparent molecular mass of 22.8 or $24.7 \mathrm{kDa}$ on SDS-PAGE (Figure 3, lane 2 or 4). The specific activities of reAuXyn $11 \mathrm{~A}$ and reAEXynM, towards $0.5 \%(\mathrm{w} / \mathrm{v})$ birchwood xylan under the standard assay conditions, were 10,437 and 9,529 $\mathrm{U} \mathrm{mg}^{-1}$, respectively. The specific activity of reAEXynM was much higher than those of the thermostable xylanase A from Thermomonospora fusca expressed in P. pastoris (117.3 $\mathrm{U} \mathrm{mg}^{-1}$ ) [21] and of commercialized thermostable xylanase $2\left(40 \mathrm{U} \mathrm{mg}^{-1}\right)$ reported from Sigma-Aldrich (St Louis, MO, USA).

Temperature characteristics of reAuXyn11A and reAEXynM The temperature optima of reAuXyn11A and reAEXynM were 50 and $70^{\circ} \mathrm{C}$, respectively (Figure $4 \mathrm{~A}$ ), while their temperature stabilities were 45 and $75^{\circ} \mathrm{C}$ (Figure 4B). After incubation at $55^{\circ} \mathrm{C}$ for 1.0 hour, reAuXyn $11 \mathrm{~A}$ retained

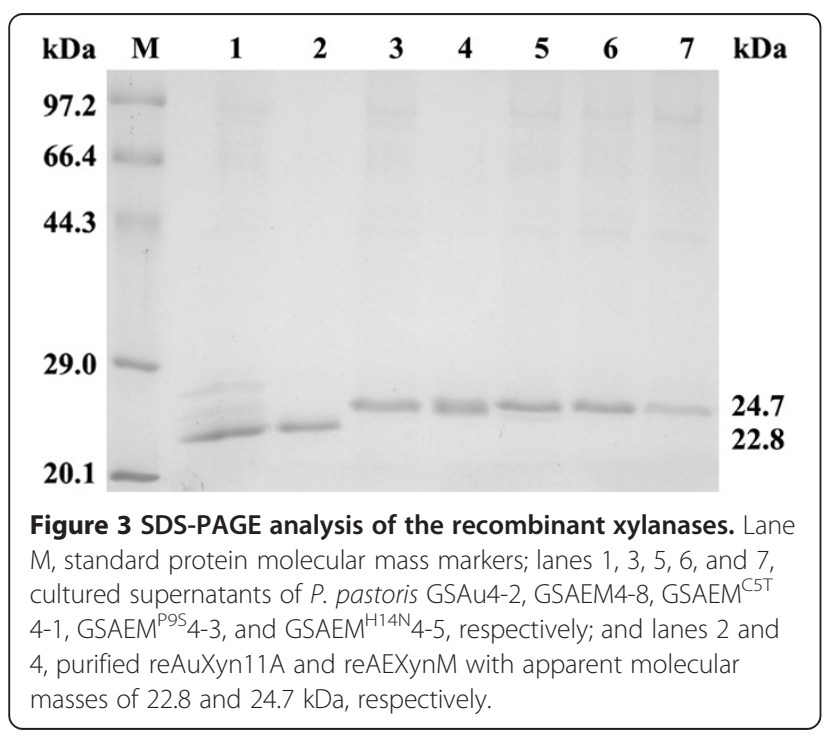

only $32.5 \%$ of its original activity, while reAEXynM retained nearly $100 \%$. Even if incubated at $85^{\circ} \mathrm{C}$, reAEXynM still retained $39.9 \%$ of its original activity.

The emission intensity of the fluorescence dye combined with hydrophobic regions of a protein was gradually increased as the protein was unfolding at high temperatures [22]. Based on this mechanism, the melting temperature $\left(T_{\mathrm{m}}\right)$ values of reAuXyn11A and reAEXynM were graphically determined from the derivative melting curve of 57.6 and $91.6^{\circ} \mathrm{C}$, respectively (Figure 5), which corresponded well to their temperature stability levels (Figure 4B). As a result, by substituting the $\mathrm{N}$-terminal 33 amino acids of AuXyn11A with the corresponding 38 ones of $E v X y n 11^{\text {TS }}$, the $T_{\mathrm{m}}$ value of reAEXynM increased by $34.0^{\circ} \mathrm{C}$ as compared with that of reAuXyn11A.

\section{Hydrolytic products from corncob xylan}

The hydrolytic products from corncob xylan by reAEXynM at different intervals were analyzed by HPLC. As the reaction time extended, the contents of xylobiose, xylotriose, xylotetraose, and xylopentaose increased, whereas that of xylohexaose decreased (Table 1). Only a trace of xylose was detected in the hydrolytic process, suggesting that reAEXynM is suitable for the production of XOSs. After incubation at $\mathrm{pH} 4.6$ and $60^{\circ} \mathrm{C}$ for 3.0 hours, the contents of xylobiose and xylotriose as the major hydrolysates from corncob xylan were 5.081 and $2.492 \mathrm{mg} \mathrm{mL}^{-1}$, respectively (Figure 6). The hydrolytic conditions (except $40^{\circ} \mathrm{C}$ ) and results of reAuXyn11A (Additional file 1) were similar to those of reAEXynM. It was reported that xylotriose as the major hydrolytic product was released from birchwood and wheat bran xylans by reBlxA with contents of 1.330 and $0.546 \mathrm{mg} \mathrm{mL}^{-1}$, respectively [23]. XOSs with low degrees of polymerization ( $\mathrm{DP}=2$ to 6 ), produced from xylans by endoxylanases, have been proven to be able to promote proliferation of bifidobacteria, the beneficial microorganisms in the human intestine. Demand for this functional food additive has shown a rapid growth over the last two decades [24].

\section{Determination of the crucial amino acids in the $\mathrm{N}$-terminus}

A total of 20 different amino acids between AEXynM and AuXyn11A were selected to identify the crucial amino acids that contribute to the high thermostability of AEXynM. After MD simulation processes, the total energy values of AEXYnM and its 20 hypothetic single mutants were calculated, respectively (Table 2). As a result, three single mutants $\left(\mathrm{AEXynM}{ }^{\mathrm{C5T}}, \mathrm{AEXynM}^{\mathrm{P} 9 \mathrm{~S}}\right.$, and $\mathrm{AEXynM}^{\mathrm{H} 14 \mathrm{~N}}$ ) with the highest total energy values were identified. Compared with AEXynM, three mutants displayed increases in total energy values from -11.66 to $-10.96,-11.16$, and $-11.25 \mathrm{~kJ} \mathrm{mmol}^{-1}$, respectively, which may contribute to their decreased thermostabilities [25]. The $\mathrm{AEXynM}^{\mathrm{C5T}}$, $\mathrm{AEXYnM}^{\mathrm{P9S}}$-, and $\mathrm{AEXynM}^{\mathrm{H} 14 \mathrm{~N}_{-}}$-encoding genes were 

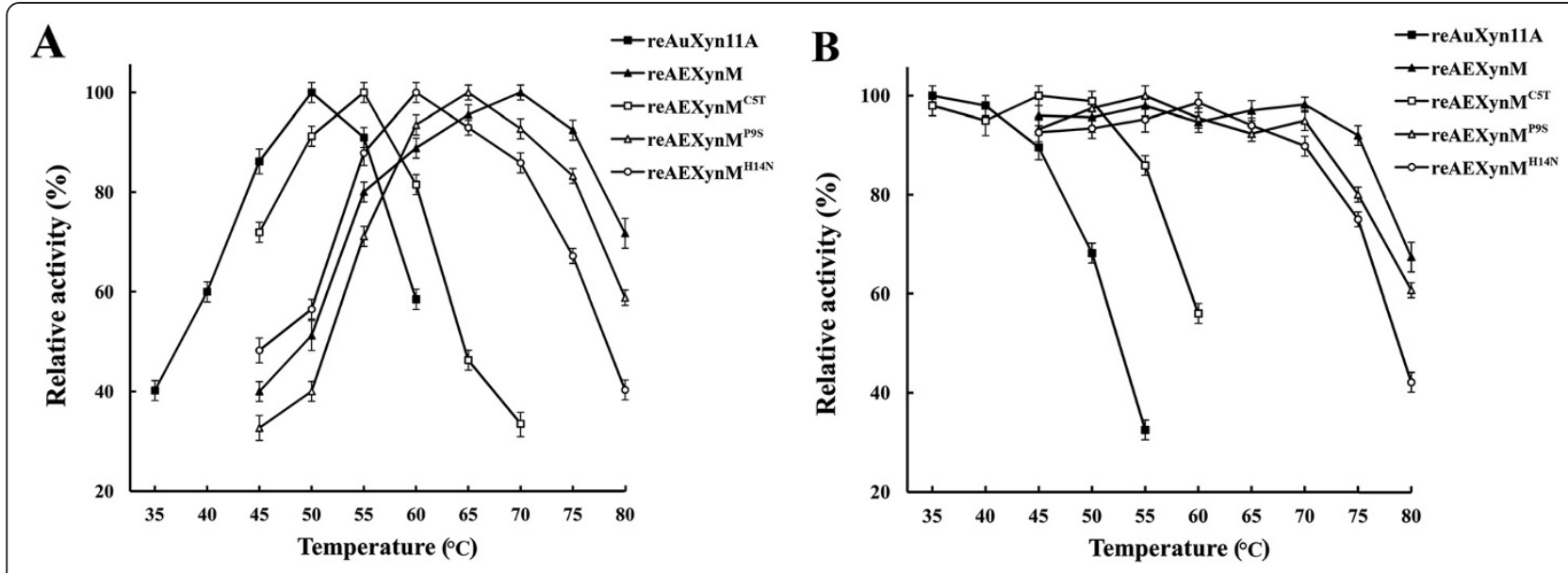

Figure 4 Temperature optimum and stability of the recombinant xylanases. (A) The temperature optima were measured under the standard assay conditions, but temperatures ranged from 35 to $60^{\circ} \mathrm{C}$ for reAuXyn $11 \mathrm{~A}$ as well as from 45 to $80^{\circ} \mathrm{C}$ for reAEXynM and its recombinant mutants. (B) To estimate the temperature stabilities, reAuXyn11A and reAEXynM ${ }^{C 5 T}$ were incubated from 35 to $60^{\circ} \mathrm{C}$ and other recombinant xylanases from 45 to $80^{\circ} \mathrm{C}$, respectively, for 1.0 hour. $\mathbf{m}$, reAuXyn11A; $\boldsymbol{\Lambda}$, reAEXynM; $\square$, reAEXYnM ${ }^{C 5 T}$; $\triangle$, reAEXynM ${ }^{\text {PgS }}$; o, reAEXynM ${ }^{H 14 N}$.

constructed as designed theoretically and expressed in $P$. pastoris, respectively. After flask expression tests, three recombinant strains, labeled as $P$. pastoris GSAEM $^{\mathrm{C} 5 \mathrm{~T}} 4-1$, GSAEM $^{\mathrm{P9S}} 4-3$, and $\mathrm{GSAEM}^{\mathrm{H} 14 \mathrm{~N}} 4-5$, were selected, expressing the highest reAEXynM ${ }^{\mathrm{C} 5 \mathrm{~T}}$, reAEXynM ${ }^{\mathrm{P} 9 \mathrm{~S}}$, and reAEXynM $^{\mathrm{H} 14 \mathrm{~N}}$ activities of 597.3, 609.2, and $558.8 \mathrm{U} \mathrm{mL}^{-1}$, respectively.

\section{Characterization of the recombinant mutants}

The recombinant mutants, reAEXynM ${ }^{\mathrm{C} 5 \mathrm{~T}}$, reAEXynM ${ }^{\mathrm{P} 9 \mathrm{~S}}$, and reAEXynM ${ }^{\mathrm{H} 14 \mathrm{~N}}$, displayed the same molecular mass $(24.7 \mathrm{kDa})$ as reAEXynM on SDS-PAGE (Figure 3, lanes 5,6 , and 7). The specific activities of purified recombinant mutants were $10,146,10,315$, and 9,876 U/mg, respectively,

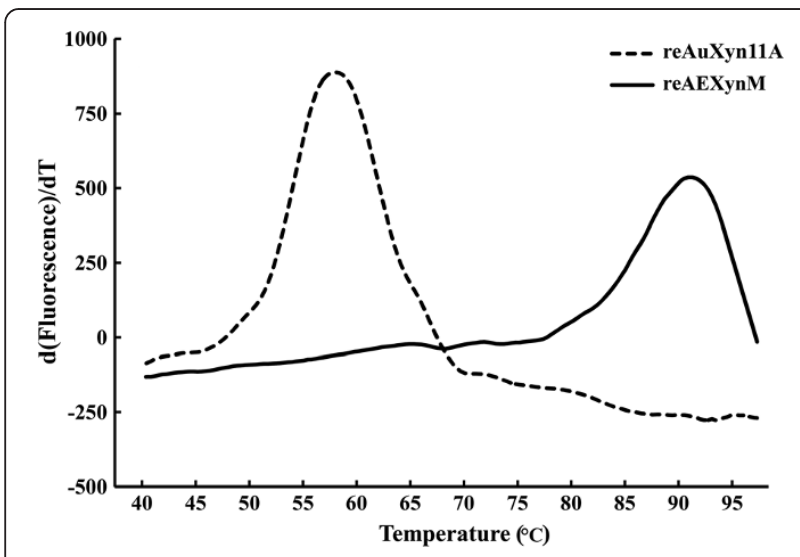

Figure 5 Derivative melting curves of reAuXyn11A (dashed line) and reAEXynM (solid line). The emission intensity of the fluorescence dye was recorded from 40 to $99^{\circ} \mathrm{C}$ at an elevated rate of $1^{\circ} \mathrm{C} \mathrm{min}^{-1}$. slightly higher than that $\left(9,529 \mathrm{U} \mathrm{mg}^{-1}\right)$ of reAEXynM. The temperature optima of mutants were 55,65 , and $60^{\circ} \mathrm{C}$, respectively (Figure $4 \mathrm{~A}$ ), lower than that $\left(70^{\circ} \mathrm{C}\right)$ of reAEXynM. To evaluate the temperature stabilities, the residual activities of mutants were measured after incubation at various temperatures for 1.0 hour (Figure 4B). Both reAEXynM ${ }^{\mathrm{P} 9 \mathrm{~S}}$ and reAEXynM ${ }^{\mathrm{H} 14 \mathrm{~N}}$ were stable at $70^{\circ} \mathrm{C}$, and reAEXynM $\mathrm{M}^{\mathrm{C} 5 \mathrm{~T}}$ at $55^{\circ} \mathrm{C}$. After incubation at $70^{\circ} \mathrm{C}$, reAEXynM ${ }^{\mathrm{C} 5 \mathrm{~T}}$ lost all of its activity, while reAEX$\mathrm{ynM}^{\mathrm{P} 9 \mathrm{~S}}$ and reAEXynM ${ }^{\mathrm{H} 14 \mathrm{~N}}$ retained 95 and $89 \%$ of their original activities, respectively. Moreover, reAEXynM ${ }^{\mathrm{P} 9 \mathrm{~S}}$ and reAEXynM ${ }^{\mathrm{H} 14 \mathrm{~N}}$ showed lower residual activities than reAEXynM after incubation at $80^{\circ} \mathrm{C}$. These analytical results demonstrated that the three single mutations had negative effects on the thermostability of AEXynM as predicted by total energy value calculation, among which one single mutation of C5T caused the most significant decrease in thermostability. In other words, $\mathrm{Cys}^{5}$, $\mathrm{Pro}^{9}$, and $\mathrm{His}^{14}$ in the replaced $\mathrm{N}$-terminus contributed mainly to the high thermostability of AEXynM.

\section{Analysis of the three-dimensional structure of AEXynM}

The three-dimensional structure of AEXynM conforms to the family 11 xylanase of the overall crystal structure, resembling a partially closed right hand (Figure 7A). It is composed mainly of one $\alpha$-helix and $15 \beta$-strands that are arranged in two mostly antiparallel $\beta$-sheets $(\beta$-sheet $\mathrm{A}$ and B). The invariant catalytic residues, $\mathrm{Glu}^{89}$ and $\mathrm{Glu}^{180}$, reside at the centre of an active region of AEXynM, where the $\beta-1,4-D$-xylosidic linkages of xylan insert and get cleaved.

The experimental results revealed that $\mathrm{Cys}^{5}$, $\mathrm{Pro}^{9}$, and $\mathrm{His}^{14}$ in the N-terminus were mainly responsible for the 
Table 1 Hydrolytic products released from corncob xylan by reAEXynM

\begin{tabular}{lcccccc}
\hline $\begin{array}{l}\text { Incubation } \\
\text { time (hours) }\end{array}$ & \multicolumn{5}{c}{ Content of the hydrolytic product $\left(\mathrm{mg} \mathrm{mL}^{-1}\right)^{\mathbf{a}}$} \\
\cline { 2 - 7 } & Xylose & Xylobiose & Xylotriose & Xylotetraose & Xylopentaose & Xylohexaose \\
\hline 0.5 & 0.033 & 0.780 & 1.635 & 0.414 & 0.161 & 0.510 \\
1.0 & 0.051 & 1.932 & 2.234 & 0.432 & 0.166 & 0.362 \\
2.0 & 0.079 & 2.621 & 2.366 & 0.442 & 0.172 & 0.353 \\
3.0 & 0.097 & 5.081 & 2.492 & 0.443 & 0.174 & 0.344 \\
\hline
\end{tabular}

${ }^{\mathrm{a}}$ The contents of hydrolytic products were analyzed by HPLC.

high thermostability of AEXynM. To elucidate the mechanism of thermostability, the intramolecular interactions relative to the three amino acid residues were analyzed using the Protein Interactions Calculator (PIC) server (Indian Institute of Science, Bangalore, India; http://pic.mbu. iisc.ernet.in) [26]. The results showed that a unique disulfide bridge $\left(\mathrm{Cys}^{5}-\mathrm{Cys}^{32}\right)$, which cannot be present in AuXyn11A devoid of $\beta$-strand A1 (Figure 7B), may confer the enhanced thermostability on AEXynM by decreasing the entropy value of protein unfolding [27]. In this work, to experimentally verify the presence of the disulfide bridge in AEXynM, the purified reAEXynM was incubated with $5.0 \mathrm{mM}$ (final concentration) dithiothreitol (DTT) in 20 $\mathrm{mM}$ Tris- $\mathrm{HCl}$ buffer $(\mathrm{pH} 8.0)$ at $40^{\circ} \mathrm{C}$ for 30 minutes, followed by measuring xylanase activity under standard assay conditions. As a result, the temperature optimum of reAEXynM treated with DTT decreased from 70 to $60^{\circ} \mathrm{C}$. Considering that DTT reduces the disulfide bridge, the decrease in thermostability of reAEXynM after treatment with DTT demonstrated the presence of the disulfide bridge in AEXynM, which greatly contributed to its high thermostability. Some researchers also reported the effect of the disulfide bridge on the thermostability of xylanases $[11,28]$.

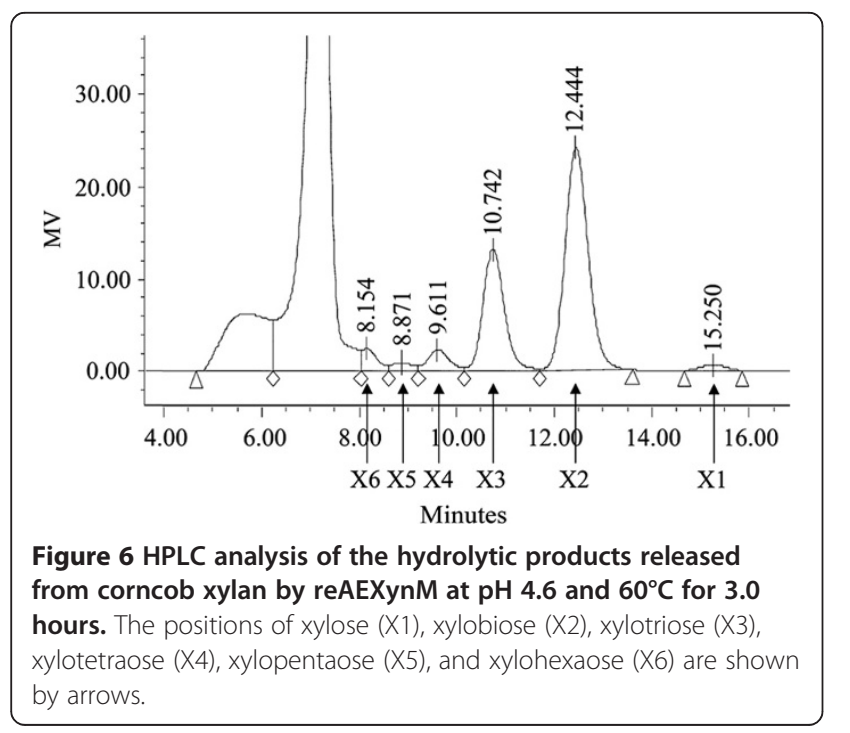

The amino acid residue Pro ${ }^{9}$, located at the front of $\beta$-strand B1, was surrounded by two hydrophobic residues $\left(\mathrm{Phe}^{21}\right.$ and $\mathrm{Trp}^{22}$ ) in the $\beta$-strand $\mathrm{B} 2$. The hydrophobic interactions of Pro ${ }^{9}$ with $\mathrm{Phe}^{21}$ and $\operatorname{Trp}^{22}$ as well as a hydrogen bond between $\mathrm{His}^{14}$ and $\mathrm{Phe}^{17}$ (Figure 7C) could stabilize the local configuration between $\beta$-strands B1 and $\mathrm{B} 2$ as a result of the high thermostability of AEXynM [10].

\section{Conclusions}

The thermostability of a mesophilic AuXyn11A was clearly improved by substituting its $\mathrm{N}$-terminal 33 amino acids with the corresponding 38 ones of a hyperthermostable $E v \mathrm{Xyn} 11^{\mathrm{TS}}$. The temperature optimum, stability, and $T_{\mathrm{m}}$ value of reAEXynM were 70,75 , and $91.6^{\circ} \mathrm{C}$, respectively, which were much higher than those of reAuXyn11A. Xylobiose and xylotriose as the major products were excised from corncob xylan by reAEXynM. In addition, it was demonstrated that $\mathrm{Cys}^{5}$, $\mathrm{Pro}^{9}$, and $\mathrm{His}^{14}$ in the replaced $\mathrm{N}$-terminus contributed mainly to the high thermostability of AEXynM. The resulting reAEXynM can become a superior candidate for industrial processes at high temperatures, exemplified by preventing microbial contamination in the production of XOSs. This work will provide an effective

Table 2 Total energy values of AEXynM and its 20 hypothetic mutants

\begin{tabular}{|c|c|c|c|}
\hline Xylanase & $\begin{array}{l}\text { Total energy value } \\
\quad\left(\mathrm{kJ} \mathrm{mmol}^{-1}\right)\end{array}$ & Xylanase & $\begin{array}{c}\text { Total energy value } \\
\left.(\mathrm{kJ} \mathrm{mmol})^{-1}\right)\end{array}$ \\
\hline$\overline{\text { AEXynM }}$ & -11.66 & & \\
\hline AEXynM ${ }^{C 5 T}$ & -10.96 & AEXynM ${ }^{P 26 G}$ & -11.40 \\
\hline AEXynM ${ }^{L 6 S}$ & -11.35 & AEXynM ${ }^{\top 28 D}$ & -11.53 \\
\hline AEXynM ${ }^{S 8 P}$ & -11.46 & AEXynM ${ }^{\text {N3OT }}$ & -11.31 \\
\hline AEXynM ${ }^{P 9 S}$ & -11.16 & $A^{2} X y n M^{F 31 Y}$ & -11.70 \\
\hline AEXynM ${ }^{Q 10 S}$ & -11.55 & AEXynM $^{C 32 T}$ & -11.53 \\
\hline$A E X y n M^{F 13 E}$ & -11.43 & AEXynM ${ }^{L 33 N}$ & -11.75 \\
\hline AEXynM ${ }^{H 14 N}$ & -11.25 & AEXynM ${ }^{L 34 G}$ & -11.32 \\
\hline AEXynM ${ }^{F 18 Y}$ & -11.39 & AEXynM ${ }^{E 35 D}$ & -11.46 \\
\hline AEXynM ${ }^{K 23 T}$ & -11.62 & AEXynM ${ }^{G 36 A}$ & -11.33 \\
\hline AEXynM ${ }^{525 G}$ & -11.34 & AEXynM ${ }^{R 38 A}$ & -11.41 \\
\hline
\end{tabular}



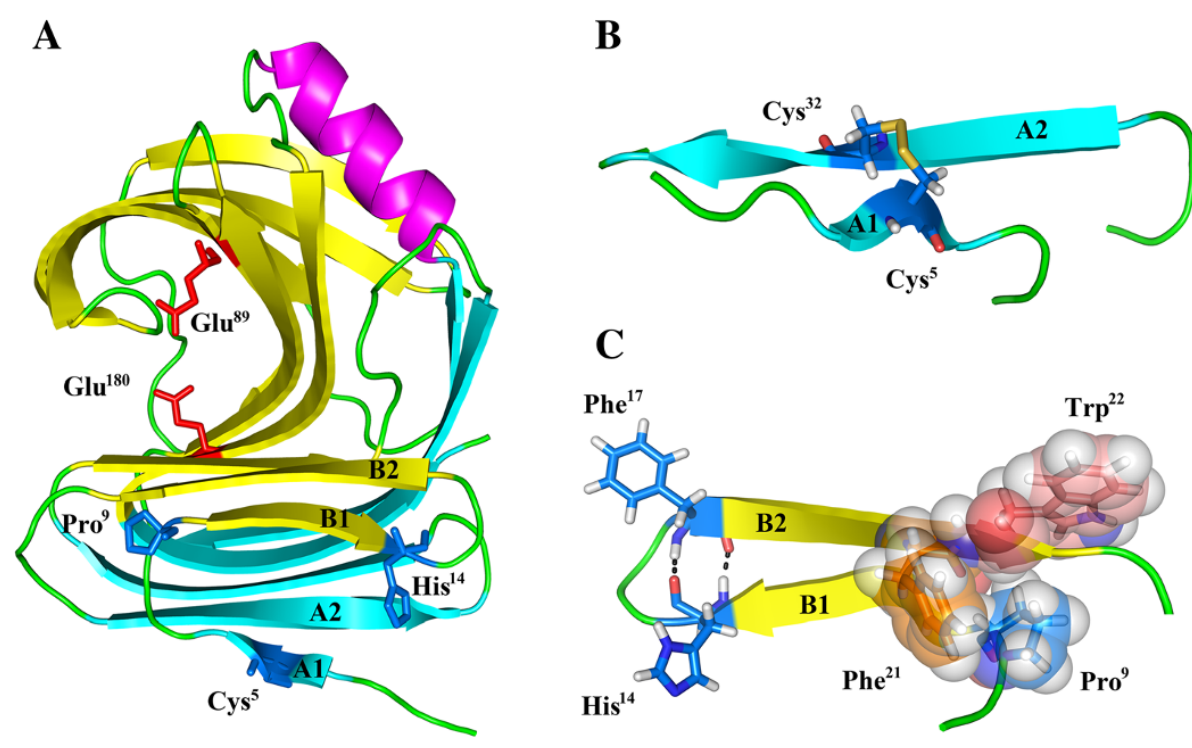

Figure 7 Analysis of the three-dimensional structure of AEXynM. (A) The three-dimensional structure of AEXynM predicted by MODELLER 9.9. Two invariant catalytic residues, $\mathrm{Glu}^{89}$ and $\mathrm{Glu}^{180}$, reside at the center of an active region. The amino acid residues $\left(\mathrm{Cys}^{5}\right.$, Pro ${ }^{9}$, and $\mathrm{His}^{14}$ ) mainly responsible for the high thermostability of AEXynM are located in $\beta$-strands A1 and B1, respectively. (B) One disulfide bridge (Cys ${ }^{5}$-Cys ${ }^{32}$ ) is illustrated in the locally magnified three-dimensional structure. (C) The residues (Pro ${ }^{9}$, Phe ${ }^{21}$, and $\operatorname{Trp}^{22}$ ) represented with spheres compose a hydrophobic interaction cluster. The hydrogen bond between $\mathrm{His}^{14}$ and $\mathrm{Phe}^{17}$ is illustrated with a dashed line.

strategy for improving the thermostabilities of other enzymes.

\section{Materials and methods}

\section{Strains, vectors, and culture media}

A. usamii E001, isolated from the soil in China as reported previously [14], was used as the donor of Auxyn11A. Escherichia coli JM109 and vector pUCm-T (Sangon, Shanghai, China) were applied for gene cloning, while $E$. coli DH5 $\alpha$ and vector pPIC9K (Invitrogen) were used for construction of the recombinant expression vectors. E. coli JM109 and DH5 $\alpha$ were cultured at $37^{\circ} \mathrm{C}$ in the Luria-Bertani medium consisting of $10 \mathrm{~g} \mathrm{~L}^{-1}$ tryptone, 5 $\mathrm{g} \mathrm{L}^{-1}$ yeast extract, and $10 \mathrm{~g} \mathrm{~L}^{-1} \mathrm{NaCl}, \mathrm{pH}$ 7.2. P. pastoris GS115 and its transformant were cultured and induced at $30^{\circ} \mathrm{C}$ in the YPD, MD, geneticin G418 containing YPD, BMGY, and BMMY media, which were prepared as described in the manual of the Multi-Copy Pichia Expression Kit.

\section{Primers for PCR}

A primer dT-PR (full name: Oligo dT-M13 Primer M4; TaKaRa, Dalian, China) was applied for reverse transcription of the first strand cDNA, from which a gene, Auxyn11A, coding for AuXyn11A was amplified with primers AuX-F and AuX-R. Primers SyX-F, SyX-R, and AuX-R were used for cloning of a hybrid xylanase AEXynM-encoding gene, AExynM. Three single mutant genes, $A E x y n M^{\mathrm{C} 5 \mathrm{~T}}, A E x-$ $y n M^{\mathrm{P9S}}$, and $A E x y n M^{\mathrm{H} 14 \mathrm{~N}}$, were constructed by PCR with the corresponding forward primers AM5-F, AM9-F, and
AM14-F and a reverse primer AuX-R, respectively. As listed in Additional file 2, all PCR primers (except dT-PR) used in this work were synthesized by Sangon.

\section{Cloning of the genes Auxyn11A and Syxyn11}

The gene Auxyn11A [GenBank: DQ302412] was amplified from the A. usamii total RNA extracted using the RNA Extraction Kit (Sangon) by RT-PCR. Meanwhile the gene Syxyn11 [GenBank: JX459567], with optimized synonymous codons that bias towards $P$. pastoris, was artificially synthesized according to the $E v \mathrm{Xyn} 11^{\mathrm{TS}}$-encoding gene sequence [GenBank: EU591743]. The two xylanase genes obtained were inserted into $\mathrm{pUCm}-\mathrm{T}$ and then transformed into E. coli JM109, respectively, followed by DNA sequencing. Two resulting recombinant $\mathrm{T}$-vectors containing the proper inserts, designated pUCm-T-Auxyn $11 A$ and pUCm-TSyxyn11, were used as the parent genes for construction of a hybrid xylanase gene, $A E x y n M$.

\section{Computational prediction of the hybrid xylanase}

The B-factor values, that is, atomic displacement parameters, of amino acid residues were generated by MD simulation towards the three-dimensional structure of a protein using the GROMACS 4.5 package (Royal Institute of Technology, Stockholm, and Uppsala University, Uppsala, Sweden; http://www.gromacs.org/), and then calculated using the B-FITTER program as described by Reetz et al. [29]. The RMSD value, which is an important index for evaluating the thermostability of a protein conformation, was defined as the $\mathrm{C}_{\alpha}$-atomic displacement parameter of a 
protein from its original three-dimensional structure to the changed one at a high temperature and a certain time. The smaller the RMSD value of a protein, the smaller its $\mathrm{C}_{\alpha}$-atomic displacement range, that is, the more thermostable its conformation [30].

In this work, the three-dimensional structure of AuXyn11A was homologically modeled by using the MODELLER 9.9 program (University of California San Francisco, San Francisco, CA, USA; http://salilab.org/modeller) based on the crystal structure of a hyperthermostable xylanase, $E v X y n 11^{\text {TS }}$, expressed in E. coli [PDB: 2VUL]. The B-factor values of AuXyn11A or EvXyn $11^{\text {TS }}$ were calculated after a $15 \mathrm{~ns}$ MD simulation process at a temperature of 300 $\mathrm{K}$. Based on the comparison of B-factor values between AuXyn11A and EvXyn11 ${ }^{\text {TS }}$, a predicted hybrid xylanase, AEXynM, was designed by substituting a suitable $\mathrm{N}$ terminal segment of AuXyn11A with the corresponding one of $E v X y n 11^{\mathrm{TS}}$. To further evaluate the thermostability of AEXynM, the three-dimensional structures of three xylanases (AuXyn11A, AEXynM, and EvXyn11 ${ }^{\mathrm{TS}}$ ) were subjected to MD simulation processes at $500 \mathrm{~K}$ for $10 \mathrm{~ns}$, respectively, followed by calculating their RMSD values using the g_rms software of the GROMACS 4.5 package.

\section{Construction of the hybrid xylanase gene}

The AEXynM-encoding gene, AExynM, was constructed by substituting the 5 '-end DNA fragment ( 99 bp in length) of Auxyn11A with the corresponding one (114 bp in length) of Syxyn11 with the megaprimer PCR method [31]. Using pUCm-T-Syxyn11 as the template, the DNA fragment (SyX) was amplified by first-round PCR with primers SyX-F (with an EcoRI site) and SyX-R at following conditions: denaturation at $94^{\circ} \mathrm{C}$ for 3 minutes; 30 cycles at $94^{\circ} \mathrm{C}$ for 30 seconds, $56^{\circ} \mathrm{C}$ for 30 seconds, $72^{\circ} \mathrm{C}$ for 15 seconds; and elongation at $72^{\circ} \mathrm{C}$ for 10 minutes. Then, the complete gene $A$ ExynM was amplified from pUCm-TAuxyn 11A by second-round PCR using fragment SyX and AuX-R (with a NotI site) as the primers under the same conditions as mentioned above, except an elongation at $72^{\circ} \mathrm{C}$ for 45 seconds in 30 cycles. The target PCR product was purified by using the EZ-10 Spin Column DNA Gel Extraction Kit (Bio Basic Canada Inc, Markham, ON, Canada) and inserted into pUCm-T, followed by transforming it into E. coli JM109. The resulting recombinant T-vector containing the gene $A E x y n M$, named pUCm-T$A E x y n M$, was confirmed by DNA sequencing.

\section{Site-directed mutagenesis of AEXynM}

For determining the crucial amino acids in the replaced $\mathrm{N}$-terminus that contributed to the high thermostability of AEXynM, 20 hypothetic single mutant xylanases were designed by substituting the N-terminal of various amino acids of AEXynM with the corresponding ones of AuXyn11A (Figure 1B and Table 2), respectively. The three-dimensional structures of AEXynM and 20 hypothetic mutants were then homologically modeled and subjected to MD simulation processes at $300 \mathrm{~K}$ for $2 \mathrm{~ns}$, respectively, followed by calculating their total energy values using the g_energy software of the GROMACS 4.5 package.

The total energy value of a protein was closely correlated with the entropy value of its unfolding [27]. It has been demonstrated that the lower the total energy value of a protein, the more thermostable its three-dimensional structure or conformation [25,27]. In this work, three hypothetic mutants $\left(\mathrm{AEXynM}^{\mathrm{C5T}}\right.$, AEXynM $^{\mathrm{P} 9 \mathrm{~S}}$, and AEX$\left.\mathrm{ynM}^{\mathrm{H} 14 \mathrm{~N}}\right)$, with the highest total energy values, were selected for site-directed mutagenesis. Their encoding genes $\left(A E x y n M^{\mathrm{C} 5 \mathrm{~T}}, A E_{x y n} M^{\mathrm{P} 9 \mathrm{~S}}\right.$, and $\left.A E x y n M^{\mathrm{H} 14 \mathrm{~N}}\right)$ were constructed by PCR, respectively. The target PCR products were gel-purified, inserted into pUCm-T, and transformed into $E$. coli JM109, respectively. The resulting recombinant T-vectors, named pUCm-T-AExyn $M^{\mathrm{C} 5 \mathrm{~T}}$, pUCm-T- $A E x$ $y n M^{\mathrm{P} 9 \mathrm{~S}}$, and pUCm-T-AExyn $M^{\mathrm{H} 14 \mathrm{~N}}$, were confirmed by DNA sequencing.

\section{Expression of the xylanase genes}

The Auxyn11A, AExynM, and three mutant genes were excised from five recombinant $\mathrm{T}$-vectors by digestion with EcoRI and NotI, and inserted into pPIC9K digested with the same enzymes, followed by transforming them into $E$. coli $\mathrm{DH} 5 \alpha$, respectively. The resulting recombinant expression vectors were then linearized with SalI, and transformed into $P$. pastoris GS115, respectively, by electroporation using Gene Pulser apparatus (Bio-Rad, Hercules, CA, USA) according to the manufacturer's instruction.

All $P$. pastoris transformants were primarily screened based on their ability to grow on a MD plate, and successively inoculated on the geneticin G418-containing YPD plates at increasing concentrations of 1.0, 2.0, and $4.0 \mathrm{mg} \mathrm{mL}^{-1}$ for the screening of multiple copies of integrated xylanase genes, respectively. $P$. pastoris transformed with pPIC9K was used as the negative control ( $P$. pastoris GSC). Expression of the xylanase gene in P. pastoris GS115 was performed according to the instruction of the MultiCopy Pichia Expression Kit with slight modification [20].

\section{Purification of the expressed recombinant xylanases}

After the $P$. pastoris transformant was induced by methanol for 72 hours, a total of $50 \mathrm{~mL}$ of cultured supernatant was brought to $45 \%$ saturation by adding solid ammonium sulfate, followed by centrifugation. Solid ammonium sulfate was then added to the supernatant up to $75 \%$ saturation. The resulting precipitate was harvested, dissolved in $4 \mathrm{~mL}$ of $20 \mathrm{mM} \mathrm{Na} \mathrm{HPO}_{4}-\mathrm{NaH}_{2} \mathrm{PO}_{4}$ buffer ( $\mathrm{pH}$ 6.5), and dialyzed against the same buffer overnight. The dialysate was concentrated to $1 \mathrm{~mL}$ by ultrafiltration using a $10 \mathrm{kDa}$ 
cut-off membrane (Millipore, Billerica, MA, USA) and then loaded onto a Sephadex G-75 column (GE Healthcare, Little Chalfont, UK; inner diameter of $1.6 \times 80 \mathrm{~cm}$ ), followed by elution with the same buffer at a flow rate of $0.3 \mathrm{~mL} \mathrm{~min}{ }^{-1}$. Aliquots of $1.5 \mathrm{~mL}$ eluent containing only a target xylanase were pooled and concentrated for further study. All purification steps were performed at $4^{\circ} \mathrm{C}$ unless stated otherwise.

\section{Enzyme activity and protein assays}

Xylanase activity was assayed by measuring the amount of reducing sugars released from birchwood xylan (SigmaAldrich), using the 3,5-dinitrosalicylic acid (DNS) method [20]. One unit $(\mathrm{U})$ of xylanase activity was defined as the amount of enzyme liberating $1 \mu \mathrm{mol}$ of reducing sugar equivalent per minute under the assay conditions (at $\mathrm{pH}$ 4.6 and $50^{\circ} \mathrm{C}$ for 15 minutes). SDS-PAGE was performed according to the method of Laemmli [32] on a $12.5 \%$ gel. The isolated proteins were visualized by staining with Coomassie Brilliant Blue R-250 (Sigma-Aldrich). The protein concentration was measured with the BCA-200 Protein Assay Kit (Thermo Scientific, Waltham, MA, USA), using BSA as the standard.

\section{Temperature optima and stabilities}

The temperature optima were measured, respectively, under the standard xylanase activity assay conditions, except temperatures ranging from 35 to $60^{\circ} \mathrm{C}$ for reAuXyn11A as well as from 45 to $80^{\circ} \mathrm{C}$ for reAEXynM and its single mutants (reAEXynM ${ }^{\mathrm{C5T}}$, reAEXynM ${ }^{\mathrm{P} 9 \mathrm{~S}}$, and reAEX$\mathrm{ynM}^{\mathrm{H} 14 \mathrm{~N}}$ ). To estimate the temperature stabilities, reAuXyn11A and reAEXynM ${ }^{\mathrm{C} 5 \mathrm{~T}}$ were incubated in the absence of substrate at various temperatures $\left(35\right.$ to $60^{\circ} \mathrm{C}$ ) and other recombinant xylanases incubated at temperatures from 45 to $80^{\circ} \mathrm{C}$, respectively, for 1.0 hour. The temperature stability in this work was defined as a temperature, at or below which the residual activity of xylanase, measured under the standard assay conditions, retained over $85 \%$ of its original activity.

\section{Measurement of the melting temperature}

The $T_{\mathrm{m}}$ is defined as a temperature, at which half of a protein's three-dimensional structure is unfolded as the temperature elevates. The higher the $T_{\mathrm{m}}$ value of a protein or enzyme, the more thermostable its three-dimensional structure [33]. The $T_{\mathrm{m}}$ value of xylanase in this work was measured using the Protein Thermal Shift (PTS) method and the PTS kit on ABI 7500 Real Time PCR apparatus (Applied Biosystems, Carlsbad, CA, USA) according to the manufacturer's instruction. The purified xylanase was mixed with fluorescence dye and placed into a 96-well PCR plate, followed by heating from 40 to $99^{\circ} \mathrm{C}$ at an elevated rate of $1^{\circ} \mathrm{C} \mathrm{min}{ }^{-1}$. Deionized water instead of protein was used as the negative control. The excitation and emission wavelengths were 490 and $530 \mathrm{~nm}$, respectively. Four replicates were performed independently. The $T_{\mathrm{m}}$ value of xylanase was considered as a temperature corresponding to the peak value in the derivative melting curve, which was plotted using the PTS software.

\section{Corncob xylan hydrolysis and HPLC analysis}

Corncob xylan, prepared by using the alkali extraction method as reported previously [34], was suspended in 20 $\mathrm{mM} \mathrm{Na} 2 \mathrm{HPO}_{4}$ citric acid buffer ( $\mathrm{pH}$ 4.6) at a concentration of $25 \mathrm{mg} \mathrm{mL}^{-1}$. A total of $40 \mathrm{~mL}$ of corncob xylan suspension was then incubated with reAEXynM (300 $\mathrm{U} \mathrm{g}^{-1}$ xylan) at $60^{\circ} \mathrm{C}$ for different intervals. The hydrolytic reaction was terminated by boiling for 10 minutes. Hydrolytic products released from xylan by reAEXynM as well as the standard D-xylose, xylobiose, xylotriose, xylotetraose, xylopentaose, and xylohexaose (Megazyme, Wicklow, Ireland) were analyzed by HPLC, respectively. Isolation of xylose and XOSs was performed with a Sugar-PakI column (Waters, Milford, MA, USA; inner diameter of $6.5 \times 300 \mathrm{~mm}$ ), using pure water as the mobile phase at a flow rate of 0.5 $\mathrm{mL} \mathrm{min}^{-1}$. The column temperature was kept at $85^{\circ} \mathrm{C}$ and the sample injection volume was $10 \mu \mathrm{L}$. Sugar peak areas were recorded using a Waters 2414 Refractive Index Detector (Waters). The content of each hydrolytic product was measured by quantifying its peak area with that of the corresponding standard D-xylose or XOS whose content was known.

\section{Additional file}

Additional file 1: HPLC analysis of the hydrolytic products released from corncob xylan by reAuXyn $11 \mathrm{~A}$ at $\mathrm{pH} 4.6$ and $40^{\circ} \mathrm{C}$ for 3.0

hours. The positions of $x y l o s e(X 1)$, xylobiose $\left(X_{2}\right)$, xylotriose $(X 3)$, xylotetraose (X4), xylopentaose (X5), and xylohexaose (X6) are shown by arrows.

Additional file 2: PCR primers for construction of the xylanase genes.

\begin{abstract}
Abbreviations
BMGY: Buffered glycerol-complex medium; BMMY: Buffered methanol-complex medium; BSA: Bovine serum albumin; Cys: Cysteine; DNS: 3,5-Dinitrosalicylic acid; DP: Degree of polymerization; DTT: Dithiothreitol; EDTA: Ethylene diamine tetraacetic acid; GH: Glycoside hydrolase; His: Histidine; HPLC: High performance liquid chromatography; MD: Molecular dynamics; PCR: Polymerase chain reaction; PIC: Protein Interactions Calculator; Pro: Proline; PTS: Protein Thermal Shift; RMSD: Root mean square deviation; RT-PCR: Reverse transcription polymerase chain reaction; $T_{m}$ : Melting temperature; XOS: xylooligosaccharide; YPD: Yeast extract peptone dextrose.
\end{abstract}

\section{Competing interests}

The authors declare that they have no competing interests.

Authors' contributions

$\mathrm{HZ}$ carried out the computational prediction, cloning, and expression. JL helped to analyze the hydrolytic products and drafted the manuscript. JW and $Y Y$ helped to purify and characterize the xylanases. MW directed the overall study and revised the manuscript. All authors read and approved the final manuscript. 


\section{Acknowledgments}

This work was financially supported by the National Nature Science Foundation of China (number: 31101229) and the Fundamental Research Funds for the Central Universities of China (number: JUDCF10056). The authors are grateful to Professor Xianzhang Wu (School of Biotechnology, Jiangnan University, Jiangsu, China) for providing technical assistance.

\section{Author details}

${ }^{1}$ State Key Laboratory of Food Science and Technology, School of Food Science and Technology, Jiangnan University, 1800 Lihu Avenue, Wuxi, Jiangsu 214122, China. 'School of Biotechnology, Jiangnan University, 1800 Lihu Avenue, Wuxi, Jiangsu 214122, China. ${ }^{3}$ Wuxi Medical School, Jiangnan University, 1800 Lihu Avenue, Wuxi, Jiangsu 214122, China.

Received: 9 September 2013 Accepted: 17 December 2013 Published: 6 January 2014

\section{References}

1. Collins T, Gerday C, Feller G: Xylanases, xylanase families and extremophilic xylanases. FEMS Microbiol Rev 2005, 29(1):3-23.

2. Singh S, Madlala AM, Prior BA: Thermomyces lanuginosus: properties of strains and their hemicellulases. FEMS Microbiol Rev 2003, 27(1):3-16.

3. Taibi Z, Saoudi B, Boudelaa M, Trigui H, Belghith H, Gargouri A, Ladjama A: Purification and biochemical characterization of a highly thermostable xylanase from Actinomadura sp. strain Cpt20 isolated from poultry compost. Appl Biochem Biotechnol 2012, 166(3):663-679.

4. Sriprang R, Asano K, Gobsuk J, Tanapongpipat S, Champreda V, Eurwilaichitr $\mathrm{L}$ : Improvement of thermostability of fungal xylanase by using site-directed mutagenesis. J Biotechnol 2006, 126(4):454-462

5. Zhang J, Siika-aho M, Puranen T, Tang M, Tenkanen M, Viikari L: Thermostable recombinant xylanases from Nonomuraea flexuosa and Thermoascus aurantiacus show distinct properties in the hydrolysis of xylans and pretreated wheat straw. Biotechnol Biofuels 2011, 4:12

6. Cai H, Shi P, Bai Y, Huang H, Yuan T, Yang P, Luo H, Meng K, Yao B: A novel thermoacidophilic family 10 xylanase from Penicillium pinophilum C1. Process Biochem 2011, 46(12):2341-2346.

7. Yoon HS, Han NS, Kim CH: Expression of Thermotoga maritima endo- $\beta$ $1,4-x y l a n a s e$ gene in $E$. coli and characterization of the recombinant enzyme. Agric Chem Biotechnol 2004, 47(3):157-160.

8. Sunna A, Bergquist PL: A gene encoding a novel extremely Thermostable $1,4-\beta$-xylanase isolated directly from an environmental DNA sample. Extremophiles 2003, 7(1):63-70.

9. Hakulinen N, Turunen O, Janis J, Leisola M, Rouvinen J: Three-dimensional structures of thermophilic $\beta-1,4-x y l a n a s e s$ from Chaetomium thermophilum and Nonomuraea flexuosa: Comparison of twelve xylanases in relation to their thermal stability. Eur J Biochem 2003, 270(7):1399-1412.

10. Kumar S, Tsai CJ, Nussinov R: Factors enhancing protein thermostability. Protein Eng 2000, 13(3):179-191

11. Wang $Y$, Fu Z, Huang $H$, Zhang $H$, Yao B, Xiong H, Turunen O: Improved thermal performance of Thermomyces lanuginosus $\mathrm{GH} 11$ xylanase by engineering of an N-terminal disulfide bridge. Bioresour Technol 2012, 112:275-279.

12. He J, Yu B, Zhang K, Ding $X$, Chen D: Thermostable carbohydrate binding module increases the thermostability and substrate-binding capacity of Trichoderma reesei xylanase 2. New Biotechnol 2009, 26(1-2):53-59.

13. Dumon C, Varvak A, Wall MA, Flint JE, Lewis RJ, Lakey JH, Morland C, Luginbuhl P, Healey S, Todaro T, et al: Engineering hyperthermostability into a $\mathrm{GH} 11$ xylanase is mediated by subtle changes to protein structure. J Biol Chem 2008, 283(33):22557-22564.

14. Wu M, Fu D, Zhu J, Xia M: Purification and some properties of two xylanases from Aspergillus usamii. J Food Sci Biotechnol 2005, 24(6):29-33.

15. Wu M, Wang J, Zhang H, Tang C, Gao J, Tan Z: Cloning and sequence analysis of an acidophilic xylanase (Xynl) gene from Aspergillus usamii E001. World J Microbiol Biotechnol 2011, 27(4):831-839.

16. Jaenicke R, Bohm G: The stability of proteins in extreme environments. Curr Opin Struct Biol 1998, 8(6):738-748.

17. Reetz MT, Carballeira JD, Vogel A: Iterative saturation mutagenesis on the basis of $B$ factors as a strategy for increasing protein thermostability. Angew Chem Int Ed 2006, 45(46):7745-7751.
18. Radestock S, Gohlke H: Exploiting the link between protein rigidity and thermostability for data-driven protein engineering. Eng Life Sci 2008, 8(5):507-522.

19. Tan Z, Li J, Wu M, Tang C, Zhang H, Wang J: High-level heterologous expression of an alkaline lipase gene from Penicillium cyclopium PG37 in Pichia pastoris. World J Microbiol Biotechnol 2011, 27(12):2767-2774.

20. Zhang H, Wu M, Li J, Gao S, Yang Y: Cloning and expression of a novel xylanase gene (Auxyn 11D) from Aspergillus usamii E001 in Pichia pastoris. Appl Biochem Biotechnol 2012, 167(8):2198-2211.

21. Sun JY, Liu MQ, Weng XY, Qian LC, Gu SH: Expression of recombinant Thermomonospora fusca xylanase A in Pichia pastoris and xylooligosaccharides released from xylans by it. Food Chem 2007, 104(3):1055-1064.

22. Niesen $\mathrm{FH}$, Berglund $\mathrm{H}$, Vedadi $\mathrm{M}$ : The use of differential scanning fluorimetry to detect ligand interactions that promote protein stability. Nat Protoc 2007, 2(9):2212-2221.

23. Liu MQ, Liu GF: Expression of recombinant Bacillus licheniformis xylanase A in Pichia pastoris and xylooligosaccharides released from xylans by it. Protein Expres Purif 2008, 57(2):101-107.

24. Brienzo M, Carvalho W, Milagres AMF: Xylooligosaccharides production from alkali-pretreated sugarcane bagasse using xylanases from Thermoascus aurantiacus. Appl Biochem Biotechnol 2010, 162(4):1195-1205.

25. Potapov V, Cohen M, Schreiber G: Assessing computational methods for predicting protein stability upon mutation: good on average but not in the details. Protein Eng Des Sel 2009, 22(9):553-560.

26. Tina KG, Bhadra R, Srinivasan N: PIC: Protein interactions calculator. Nucleic Acids Res 2007, 35:W473-W476.

27. Le QAT, Joo JC, Yoo YJ, Kim YH: Development of thermostable Candida antarctica lipase $B$ through novel in silico design of disulfide bridge. Biotechnol Bioeng 2012, 109(4):867-876.

28. Turunen O, Etuaho K, Fenel F, Vehmaanpera J, Wu XY, Rouvinen J, Leisola $\mathrm{M}$ : A combination of weakly stabilizing mutations with a disulfide bridge in the a-helix region of Trichoderma reesei endo-1,4- $\beta$-xylanase II increases the thermal stability through synergism. J Biotechno/ 2001 88(1):37-46.

29. Reetz MT, Carballeira JD: Iterative saturation mutagenesis (ISM) for rapid directed evolution of functional enzymes. Nat Protoc 2007, 2(4):891-903.

30. Badieyan S, Bevan DR, Zhang C: Study and design of stability in GH5 cellulases. Biotechnol Bioeng 2012, 109(1):31-44.

31. Xie ZH, Shi XJ: Fast and almost $100 \%$ efficiency site-directed mutagenesis by the megaprimer PCR method. Prog Biochem Biophys 2009, 36(11):1490-1494.

32. Laemmli UK: Cleavage of structural proteins during the assembly of the head of bacteriophage T4. Nature 1970, 227(5259):680-685.

33. Jang MK, Lee SW, Lee DG, Kim NY, Yu KH, Jang HJ, Kim S, Kim A, Lee SH: Enhancement of the thermostability of a recombinant $\beta$-agarase, AgaB, from Zobellia galactanivorans by random mutagenesis. Biotechnol Lett 2010, 32(7):943-949.

34. Lin YS, Tseng MJ, Lee WC: Production of xylooligosaccharides using immobilized endo-xylanase of Bacillus halodurans. Process Biochem 2011, 46(11):2117-2121.

doi:10.1186/1754-6834-7-3

Cite this article as: Zhang et al:: Determinants for the improved thermostability of a mesophilic family 11 xylanase predicted by computational methods. Biotechnology for Biofuels 2014 7:3. 